\title{
Idioms in the World: A Focus on Processing
}

\author{
Elena S. Kulkova* and Martin H. Fischer ${ }^{\dagger}$ \\ Department of Psychology, University of Potsdam, Potsdam, Germany
}

Keywords: embodiment, figurative language, metaphor, idiom, processing

Recent experiment-based psycho- and neuro-linguistic research brought new insights into language processing mechanisms and meaning representation in the brain. More specifically, it highlighted the dynamic nature of brain connections and a constant interplay between distributed neuronal circuits during meaning processing. These developments led to a shift from an amodal view, which perceives conceptual information activation as parallel to and independent from adjoining neural activation in sensorimotor circuits (Mahon and Caramazza, 2008; Meteyard et al., 2012), to the embodied cognition view that highlights the role of sensorimotor experience in the formation of flexible, distributed conceptual representations encompassing features acquired via different perceptual modalities (Fischer and Zwaan, 2008; Barsalou, 2010). Embodied cognition, therefore, suggests that conceptual knowledge and, consequently, semantic knowledge are grounded in bodily experience and situated actions (Glenberg et al., 2008; Pulvermüller, 2013). However, currently there is a tendency toward perceiving embodied and disembodied views not as mutually exclusive distinct theories, but as bridging a gap between them. The hub and spoke model and the sensorymotor model demonstrate attempts to integrate the amodal and modality-specific views (see Mahon, 2015).

A broad range of behavioral, physiological, and neuroimaging data demonstrating co-activation of language- and action-related brain areas support this claim with regard to concrete language (Binder et al., 2005; Pulvermüller et al., 2005; Barsalou, 2008; Hauk et al., 2008). However, the data are less conclusive with regard to figurative expressions, which constitute a significant part of language. One of the reasons is that figurative language subsumes a wide variety of heterogeneous phenomena (metonymy, idioms, metaphors, proverbs, hyperbole, irony) which differ syntactically (from phrasal verbs to compounds and even sentences), as well as in their properties (familiarity, ambiguity, transparency, compositionality, salience, predictability) and essential features (although both irony and hyperbole are based on cognitive contrast, it is a contrast of kind for irony and a contrast in magnitude for hyperbole; Hsiao and Lily, 2010). This diversity and complexity of nonliteral language types does not allow for clear-cut and strictly defined boundaries; it has led to a distinction of non-literal phenomena not dichotomously, but along a conventionality continuum (Cacciari and Papagno, 2012).

Secondly, the linguistic phenomena, embraced by the broad term "non-literal language" have been analyzed to different degrees of detail. Specifically, different aspects of metaphor production comprehension and use have been extensively studied (Gibbs, 2008, 2015; Schmidt and Seger, 2009; Bambini et al., 2011; Gibbs and Colston, 2012; Forgács et al., 2014; Obert et al., 2014; Lai and Desai, 2016; Briner et al., 2018; Rataj et al., 2018; Reilly et al., 2019). Furthermore, metaphors represent a powerful cognitive device guided by environmental experiences, which enabled the studies of metaphor framing influences not only on linguistic communication per se, but also on judgments, reasoning, intentions, and actions (Robins and Mayer, 2000; Slepian et al., 2010; Thibodeau and Boroditsky, 2011, 2013; Landau et al., 2014; Marin et al., 2014; Hauser and Schwarz, 2015; Elmore and Luna-Lucero, 2017; Thibodeau et al., 2017). Despite considerable research (Gibbs and Nayak, 1989; Cacciari and Tabossi, 1993; Mashal et al., 2008; Vulchanova et al., 2011; Cuccio et al., 2014; Häuser et al., 2016; Cacciari et al., 2018), the study of idioms still leaves open for debate the 
questions of defining idioms or differentiating them from other types of non-literal expressions (Cacciari, 2014). One of the main confusions is in defining idioms from metaphors, as it was debated whether idiom processing is possible without constant recourse to conceptual metaphors (Owens, 2016). However, although some idioms are indeed derived from metaphors and can still be partially motivated by conceptual mappings between domains (Gibbs, 1992), idioms as a class comprising syntactically and compositionally differing phenomena (Caillies and Butcher, 2007) are divergent from metaphors. The crucial difference is that idiomatic meaning is predominantly fixed and conventional, and it can be modified but not changed when used in various contexts. Metaphoric meaning, in turn, is flexible and intricate, can be profoundly changed by the context, and therefore always requires online construction (Cacciari, 2014; Bambini et al., 2016). Distinctive neural correlates for processing of idioms (left MTG and left IFG, involved in selection-inhibition operations) and metaphors [left precentral gyrus (BA 6), linking concrete and abstract domains and the left inferior parietal lobe (IPL), executing higher-order cognitive motor functions; Fogassi and Luppino, 2005] also argue against conflating them.

Disregarding these principal differences between the two linguistic forms results in their interchangeable use (e.g., Aziz-Zadeh et al., 2006), which, in turn, may posit serious confoundment, as comprehending these figurative devices that have different mental representations engages dissimilar cognitive mechanisms; based on both semantic and structural analysis of meaning and retrieval from semantic memory during idiom processing, and focused on the conceptual models and templates underlying metaphor meaning construction. Vulchanova et al. (2019) provide a detailed overview of the models of figurative language processing.

Recent studies on processing non-literal expressions with action-related semantics reported activation of motoric brain areas during either literal (Raposo et al., 2009), metaphoric (Desai et al., 2011), or only during metaphor but not idiom processing (Cacciari et al., 2011; Desai et al., 2013). Only limited publications present evidence of sensorimotor engagement during idiomatic meaning comprehension (Boulenger et al., 2009, 2012). Overall, the studies emphasize the role of context in meaning disambiguation and suggest that an increase in abstractness of the language stimuli leads to a decrease in the sensorimotor system's involvement (especially in case of idioms). However, these results could be interpreted not in favor of idiom disembodiment, but as a demonstration of different processing schemas that idioms and metaphors employ: the dual-reference

\section{REFERENCES}

Aziz-Zadeh, L., Wilson, S. M., Rizzolatti, G., and Iacoboni, M. (2006). Congruent embodied representations for visually presented actions and linguistic phrases describing actions. Curr. Biol. 16, 1818-1823. doi: 10.1016/j.cub.2006. 07.060

Bambini, V., Bertini, C., Schaeken, W., Stella, A., and Di Russo, F. (2016). Disentangling metaphor from context: an ERP study. Front. Psychol. 7:559. doi: 10.3389/fpsyg.2016.00559 idiomatic nature enables engagement of a hybrid processing mechanism that encompasses both compositional and holistic context-based analysis during idiom comprehension (Caillies and Butcher, 2007; Boulenger et al., 2012; Cacciari and Pesciarelli, 2013). Metaphors, which retain stronger links to the original meaning of the constituent words, rely more on online mental simulation to compute complex, flexible meanings.

Engaging different processing mechanisms may result in spatially and temporally different patterns of neurocognitive involvement (Rapp et al., 2012; Yang and Shu, 2016). For example, Cacciari et al. (2011) reported no motor engagement in idiom processing, but single-pulse TMS applied at the end of sentences to register meaning-induced MEPs could be inefficient to record idiom-induced motor activation, since idioms are processed online (mentally simulated) only until the idiom is recognized, and then a switch to the non-compositional mode (retrieval from semantic memory) occurs. Lack of motor engagement during idiom comprehension can be explained by heterogeneity of idioms: e.g., Raposo et al. (2009) used highly familiar and opaque idioms, which minimized the need for mental simulation during their processing and consequently may have reduced the level of sensorimotor cortical activation. Therefore, idiomatic meaning may be less embodied compared to metaphoric meaning, but not totally disembodied.

This evidence highlights the need for a more profound exploration of properties specific to figurative language types and subtypes of each phenomenon, which could considerably benefit present-stage figurative language research and promote a better understanding of the mechanisms the human brain employs for their acquisition, production, and processing. This will provide an integrative theoretical model that can more comprehensively and consistently outline the cognitive mechanisms and neural circuitry underlying processing of heterogeneous and multifaceted figurative language. Taken together, it will inform the development of more precise neuro-cognitive models, support AI applications and enhance understanding of language processing in general.

\section{AUTHOR CONTRIBUTIONS}

$\mathrm{EK}$ and MF have contributed equally to this submission.

\section{FUNDING}

This study was supported by University of Potsdam, library funds. 
Barsalou, L. W. (2010). Grounded cognition: past, present, and future. Top. Cogn. Sci. 2, 716-724. doi: 10.1111/j.1756-8765.2010.01115.x

Binder, J. R., Westbury, C. F., McKiernan, K. A., Possing, E. T., and Medler, D. A. (2005). Distinct brain systems for processing concrete and abstract concepts. J. Cogn. Neurosci. 17, 905-917. doi: 10.1162/0898929054021102

Boulenger, V., Hauk, O., and Pulvermüller, F. (2009). Grasping ideas with the motor system: semantic somatotopy in idiom comprehension. Cereb. Cortex 19, 1905-1914. doi: 10.1093/cercor/bhn217

Boulenger, V., Shtyrov, Y., and Pulvermüller, F. (2012). When do you grasp the idea? MEG evidence of simultanous idiom understanding. Neuroimage 59, 3502-3513. doi: 10.1016/j.neuroimage.2011.11.011

Briner, S. W., Schutzenhofer, M. C., and Virtue, S. M. (2018). Hemispheric processing in conventional metaphor comprehension: the role of general knowledge. Neuropsychologia 114, 101-109. doi: 10.1016/j.neuropsychologia.2018.03.040

Cacciari, C. (2014). Processing multiword idiomatic strings: many words in one? Ment. Lex. 9, 267-293. doi: 10.1075/ml.9.2.05cac

Cacciari, C., Bolognini, N., Senna, I., Pellicciari, M. C., Miniussi, C., and Papagno, C. (2011). Literal, fictive and metaphorical motion sentences preserve the motion component of the verb: a TMS study. Brain Lang. 119, 149-157. doi: 10.1016/j.bandl.2011.05.004

Cacciari, C., Corradini, P., and Ferlazzo, F. (2018). Cognitive and personality components underlying spoken idiom comprehension in context. An exploratory study. Front. Psychol. 9:659. doi: 10.3389/fpsyg.2018.00659

Cacciari, C., and Papagno, C. (2012). "Neuropsychological and neurophysiological correlates of idiom understanding: how many hemispheres are involved," The Handbook of the Neuropsychology of Language, ed M. Faust (Chichester, UK: Wiley-Blackwell Publishing Ltd.), 368-385. doi: 10.1002/9781118432501.ch18

Cacciari, C., and Pesciarelli, F. (2013). Motor activation in literal and non-literal sentences: does time matter? Front. Hum. Neurosci. 7:202. doi: $10.3389 /$ fnhum.2013.00202

Cacciari, C., and Tabossi, P. (1993). Idioms. Processing, Structure and Interpretation. Hillsdale, NJ; Hove: Lawrence Erlbaum Associates.

Caillies, S., and Butcher, K. (2007). Processing of idiomatic expressions: evidence for a new hybrid view. Metaphor Symbol 22, 79-108. doi: $10.1080 / 10926480709336754$

Cuccio, V., Ambrosecchia, M., Ferri, F., Carapezza, M., Piparo, F. L., Fogassi, L., et al. (2014). How the context matters. Literal and figurative meaning in the embodied language paradigm. PLOS ONE 9:e115381. doi: 10.1371/journal.pone. 0115381

Desai, R. H., Binder, J. R., Conant, L. L., Mano, Q. R., and Seidenberg, M. S. (2011). The neural career of sensory-motor metaphors. J. Cogn. Neurosci. 23, 2376-2386. doi: 10.1162/jocn.2010.21596

Desai, R. H., Conant, L. L., Binder, J. R., Park, H., and Seidenberg, M. S. (2013). A piece of the action: modulation of sensory-motor regions by action idioms and metaphors. Neuroimage 83, 862-869. doi: 10.1016/j.neuroimage.2013.07.044

Elmore, K. C., and Luna-Lucero, M. (2017). Light bulbs or Seeds? How metaphors for ideas influence judgments about Genius. Soc. Psychol. Pers. Sci. 8, 200-208. doi: $10.1177 / 1948550616667611$

Fischer, M. H., and Zwaan, R. A. (2008). Embodied language: a review of the role of the motor system in language comprehension. Q. J. Exp. Psychol. 61, 825-850. doi: $10.1080 / 17470210701623605$

Fogassi, L., and Luppino, G. (2005). Motor functions of the parietal lobe. Curr. Opin. Neurobiol. 15, 626-631. doi: 10.1016/j.conb.2005.10.015

Forgács, B., Lukács, Á., and Pléh, C. (2014). Lateralized processing of novel metaphors: disentangling figurativeness and novelty. Neuropsychologia 56, 101-109. doi: 10.1016/j.neuropsychologia.2014.01.003

Gibbs R. W. Jr. (2015). Do pragmatic signals affect conventional metaphor understanding? A failed test of deliberate metaphor theory. J. Pragmat. 90, 77-87. doi: 10.1016/j.pragma.2015.05.021

Gibbs R. W. Jr. (ed.) (2008). The Cambridge Handbook of Metaphor and Thought. New York, NY: Cambridge University Press. doi: 10.1017/CBO9780511816802

Gibbs R. W. Jr., and Colston, H. L. (2012). Interpreting Figurative Meaning. New York, NY: Cambridge University Press. doi: 10.1017/CBO9781139168779

Gibbs R. W. Jr., and Nayak, N. P. (1989). Psycholinguistic studies on the syntactic behavior of idioms. Cogn. Psychol. 21, 100-138. doi: 10.1016/0010-0285(89)90004-2

Gibbs, R. W. (1992). What do idioms really mean?. J Mem Lang, 31, 485-506.
Glenberg, A. M., Sato, M., Cattaneo, L., Riggio, L., Palombo, D., and Buccino, G. (2008). Processing abstract language modulates motor system activity. Q. J. Exp. Psychol. 61, 905-919. doi: 10.1080/17470210701625550

Hauk, O., Shtyrov, Y., and Pulvermüller, F. (2008). The time course of action and action-word comprehension in the human brain as revealed by neurophysiology. J. Physiol. Paris 102, 50-58. doi: 10.1016/j.jphysparis.2008.03.013

Hauser, D. J., and Schwarz, N. (2015). The war on prevention: Bellicose cancer metaphors hurt (some) prevention intentions. Pers. Soc. Psychol. Bull. 41, 66-77. doi: 10.1177/0146167214557006

Häuser, K. I., Titone, D. A., and Baum, S. R. (2016). The role of the ventro-lateral prefrontal cortex in idiom comprehension: an rTMS study. Neuropsychologia 91, 360-370. doi: 10.1016/j.neuropsychologia.2016.09.003

Hsiao, C. H., and Lily, I. (2010). Metaphor and hyperbolic expressions of emotion in Mandarin Chinese conversation. J. Pragmat. 42, 1380-1396. doi: 10.1016/j.pragma.2009.09.006

Lai, V. T., and Desai, R. H. (2016). The grounding of temporal metaphors. Cortex 76, 43-50. doi: 10.1016/j.cortex.2015.12.007

Landau, M. J., Oyserman, D., Keefer, L. A., and Smith, G. C. (2014). The college journey and academic engagement: how metaphor use enhances identity-based motivation. J. Pers. Soc. Psychol. 106, 679. doi: 10.1037/a0036414

Mahon, B. Z. (2015). What is embodied about cognition? Lang. Cogn. Neurosci. 30, 420-429. doi: 10.1080/23273798.2014.987791

Mahon, B. Z., and Caramazza, A. (2008). A critical look at the embodied cognition hypothesis and a new proposal for grounding conceptual content. J. Physiol. Paris 102, 59-70. doi: 10.1016/j.jphysparis.2008.03.004

Marin, A., Reimann, M., and Castaño, R. (2014). Metaphors and creativity: direct, moderating, and mediating effects. J. Consum. Psychol. 24, 290-297. doi: 10.1016/j.jcps.2013.11.001

Mashal, N., Faust, M., Hendler, T., and Jung-Beeman, M. (2008). Hemispheric differences in processing the literal interpretation of idioms: converging evidence from behavioral and fMRI studies. Cortex 44, 848-860. doi: 10.1016/j.cortex.2007.04.004

Meteyard, L., Cuadrado, S. R., Bahrami, B., and Vigliocco, G. (2012). Coming of age: a review of embodiment and the neuroscience of semantics. Cortex 48, 788-804. doi: 10.1016/j.cortex.2010.11.002

Obert, A., Gierski, F., Calmus, A., Portefaix, C., Declercq, C., Pierot, L., et al. (2014). Differential bilateral involvement of the parietal gyrus during predicative metaphor processing: an auditory fMRI study. Brain Lang. 137, 112-119. doi: 10.1016/j.bandl.2014.08.002

Owens, J. (2016). The lexical nature of idioms. Lang. Sci. 57, 49-69. doi: 10.1016/j.langsci.2016.05.004

Pulvermüller, F. (2013). How neurons make meaning: brain mechanisms for embodied and abstract-symbolic semantics. Trends Cogn. Sci. 17, 458-470. doi: 10.1016/j.tics.2013.06.004

Pulvermüller, F., Hauk, O., Nikulin, V. V., and Ilmoniemi, R. J. (2005). Functional links between motor and language systems. Eur. J. Neurosci. 21, 793-797. doi: 10.1111/j.1460-9568.2005.03900.x

Raposo, A., Moss, H. E., Stamatakis, E. A., and Tyler, L. K. (2009). Modulation of motor and premotor cortices by actions, action words and action sentences. Neuropsychologia, 47, 388-396.

Rapp, A. M., Mutschler, D. E., and Erb, M. (2012). Where in the brain is nonliteral language? A coordinate-based meta-analysis of functional magnetic resonance imaging studies. Neuroimage 63, 600-610. doi: 10.1016/j.neuroimage.2012.06.022

Rataj, K., Przekoracka-Krawczyk, A., and van der Lubbe, R. H. (2018). On understanding creative language: the late positive complex and novel metaphor comprehension. Brain Res. 1678, 231-244. doi: 10.1016/j.brainres.2017. 10.030

Reilly, M., Howerton, O., and Desai, R. H. (2019). Time-course of motor involvement in literal and metaphoric action sentence processing: A TMS study. Front. Psychol. 10:371. doi: 10.3389/fpsyg.2019.00371

Robins, S., and Mayer, R. E. (2000). The metaphor framing effect: metaphorical reasoning about text-based dilemmas. Discourse Process. 30, 57-86. doi: 10.1207/S15326950dp3001_03

Schmidt, G. L., and Seger, C. A. (2009). Neural correlates of metaphor processing: the roles of figurativeness, familiarity and difficulty. Brain Cogn. 71, 375-386. doi: 10.1016/j.bandc.2009.06.001 
Slepian, M. L., Weisbuch, M., Rutchick, A. M., Newman, L. S., and Ambady, N. (2010). Shedding light on insight: priming bright ideas. J. Exp. Soc. Psychol. 46, 696-700. doi: 10.1016/j.jesp.2010.03.009

Thibodeau, P. H., and Boroditsky, L. (2011). Metaphors we think with: the role of metaphor in reasoning. PLoS ONE 6:e16782. doi: 10.1371/journal.pone.0016782

Thibodeau, P. H., and Boroditsky, L. (2013). Natural language metaphors covertly influence reasoning. PLoS ONE 8:e52961. doi: 10.1371/journal.pone.0 052961

Thibodeau, P. H., Hendricks, R. K., and Boroditsky, L. (2017). How linguistic metaphor scaffolds reasoning. Trends Cogn. Sci. 21, 852-863. doi: 10.1016/j.tics.2017.07.001

Vulchanova, M., Milburn, E., Vulchanov, V., and Baggio, G. (2019). Boon or Burden? The role of compositional meaning in figurative language processing and acquisition. J Logic Lang Information, 1-29. doi: $10.1007 /$ s10849-019-09282-7
Vulchanova, M., Vulchanov, V., and Stankova, M. (2011). Idiom comprehension in the first language: a developmental study. Vigo Int. J. Appl. Linguist. 8, 207-234.

Yang, J., and Shu, H. (2016). Involvement of the motor system in comprehension of non-literal action language: a meta-analysis study. Brain Topogr. 29, 94-107. doi: 10.1007/s10548-015-0427-5

Conflict of Interest Statement: The authors declare that the research was conducted in the absence of any commercial or financial relationships that could be construed as a potential conflict of interest.

Copyright (c) 2019 Kulkova and Fischer. This is an open-access article distributed under the terms of the Creative Commons Attribution License (CC BY). The use, distribution or reproduction in other forums is permitted, provided the original author(s) and the copyright owner(s) are credited and that the original publication in this journal is cited, in accordance with accepted academic practice. No use, distribution or reproduction is permitted which does not comply with these terms. 